\title{
Clinical and Cost Efficacy of Advanced Wound Care Matrices for Venous Ulcers
}

\author{
Cheryl S. Hankin, PhD; John Knispel, MD; Maria Lopes, MD; \\ Amy Bronstone, PhD; and Erik Maus, MD
}

\begin{abstract}
BACKGROUND: In the United States, venous leg ulcers (VLUs) are commonly associated with substantial disability, impaired quality of life, and high economic costs. Compression therapy, which has remained the standard care for VLUs over several decades, is often insufficient to heal VLUs in a timely manner. VLU-related treatment costs are directly related to time to achieve complete wound closure. Advanced wound care matrices (AWCMs) developed to stimulate wound healing may reduce VLU-related costs associated with delayed healing. Randomized controlled trials (RCTs) have evaluated the wound-healing efficacy of several AWCMs in patients with VLUs. However, comparisons of products' clinical and cost efficacy, which may guide clinical and formulary determinations, are lacking.
\end{abstract}

OBJECTIVE: To evaluate, in terms of number needed to treat (NNT), the comparative clinical and cost efficacy of targeted AWCMs as adjuncts to compression therapy for the treatment of chronic VLUs from the U.S. health care system (payer) perspective.

METHODS: A review of published articles (from the earliest available Medline publication date to June 1,2011 ) identified RCTs evaluating complete wound closure rates for up to 24 weeks in patients with VLUs treated with targeted AWCMs (Apligraf, Oasis, or Talymed) plus compression therapy compared with compression therapy alone. The most favorable estimates of product efficacy (i.e., those that were statistically significant compared with compression therapy) were used. These included statistically adjusted results for Apligraf as reported in the product insert and the biweekly application for Talymed. Based on the reported efficacy of targeted AWCMs, we calculated the NNT to achieve 1 additional treatment success (i.e., complete wound closure) over that which was achieved with standard therapy alone; $95 \%$ Cls were estimated using the Wilson score method proposed by Newcombe. Cost efficacy, defined as the incremental cost per additional successfully treated patient, was then calculated by multiplying the NNT associated with each treatment by the product acquisition cost per treated VLU episode.

RESULTS: One study for each of 3 targeted AWCMs (Apligraf $[n=130$ treatment, $n=110$ control]; 0asis Wound Matrix [ $n=62$ treatment, $n=58$ control]; and Talymed [ $n=22$ treatment, $n=20$ control]) met inclusion criteria. Study designs and wound characteristics varied. Average VLU sizes were $1 \mathrm{~cm}^{2}, 10-12 \mathrm{~cm}^{2}$, and $10-13 \mathrm{~cm}^{2}$ in the studies of Apligraf, Oasis, and Talymed, respectively. Ulcer duration exceeded 12 months for $50 \%$ of patients in the Apligraf study and was at least 7 months for $47 \%$ of patients in the 0asis study; patients with ulcers exceeding 6 months were excluded from the study of Talymed. Length of follow-up was 24 weeks for Apligraf, 12 weeks for Oasis, and 20 weeks for Talymed. NNT point estimates of clinical efficacy were 2 for Talymed, 5 for 0asis, and 6 for Apligraf; $95 \%$ Cls ranged from 2 to 8 for Talymed, 3 to 24 for Apligraf, and 3 to 39 for Oasis. Incremental costs $(95 \% \mathrm{Cls})$ per additional successfully treated patient were $\$ 1,600(\$ 1,600-\$ 6,400)$ for Talymed, $\$ 3,150(\$ 1,890-\$ 24,570)$ for Oasis, and \$29,952 (\$14,976-\$119,808) for Apligraf.

CONCLUSIONS: The most expensive AWCM for the treatment of VLUs did not appear to provide the greatest comparative clinical or cost efficacy. Conclusions must be tempered by the small number of available stud- ies $(n=3)$, variability in trial duration (from 12 to 24 weeks) and baseline wound characteristics, and limitations in study quality. Given the high prevalence, economic burden, and substantial disability of VLUs, and the wide variation in costs for AWCMs, payers need more high-quality head-tohead comparisons to guide coverage and reimbursement determinations for these products.

J Manag Care Pharm. 2012;18(5):375-84

Copyright $\odot 2012$, Academy of Managed Care Pharmacy. All rights reserved.

\section{What is already known about this subject}

- An estimated 600,000 Americans are affected by venous leg ulcers (VLUs) each year at a cost of $\$ 1.5$ to $\$ 3.5$ billion to the health care system.

- Compression therapy, which has long been the standard of care for VLUs, has inadequate success rates, with 35\%-50\% of ulcers remaining unhealed after 6 months.

- Treatment costs for VLUs, which are directly related to time to achieve complete closure, average approximately $\$ 4,000$ per month and \$16,000 per treatment episode.

- Randomized controlled trials (RCTs) have demonstrated the promising efficacy of several advanced wound care matrices (AWCMs) for the treatment of VLUs as adjuncts to compression therapy. Given the absence of head-to-head studies, other means of comparing the clinical and cost efficacy of AWCMs for VLUs are needed to inform clinical practice and payer determinations.

\section{What this study adds}

- In calculations based on RCTs of small patient samples with varying inclusion/exclusion criteria and baseline wound characteristics, the clinical efficacy of targeted AWCMs, defined as number needed to treat (NNT; 95\% CI) to achieve 1 additional successfully treated patient using targeted AWCMs as adjuncts to compression therapy compared with compression therapy alone, was 2 (2 to 8) for Talymed, 5 (3 to 39) for Oasis, and 6 (3 to 24) for Apligraf.

- The cost efficacy (95\% CI) of targeted AWCMs, defined as the incremental cost to achieve 1 additional successfully treated patient as an adjunct to compression therapy, was $\$ 1,600$ (\$1,600-\$6,400) for Talymed, $\$ 3,150$ (\$1,890-\$24,570) for Oasis, and $\$ 29,952$ (\$14,976-\$119,808) for Apligraf.

- Given the wide variation in costs of AWCMs, payers must carefully compare cost efficacy when determining the relative value of these products. 
$\mathrm{T}$ he term "skin ulcers" refers to a heterogeneous group of wound types that includes diabetic foot ulcers, pressure ulcers, acute surgical wounds, and venous leg ulcers (VLUs). VLUs, also known as varicose or stasis ulcers, are defined by a loss of skin below the knee in response to venous insufficiency and account for the majority (70\%-90\%) of lowerextremity ulcers. ${ }^{1,2}$ An estimated $1 \%$ of adults of all ages will develop a VLU at some point in their lives, ${ }^{3}$ and approximately 600,000 Americans suffer from VLUs each year. ${ }^{4}$ Although VLUs can occur at any age, ${ }^{5}$ the elderly are at greatest risk. ${ }^{3}$ Each year, VLUs are estimated to cost the U.S. health care system $\$ 1.5$ to $\$ 3.0$ billion, ${ }^{6}$ with the greatest cost burden borne by Medicare. ${ }^{7}$ These costs do not include the financial toll (as yet not estimated) imposed by VLU-related decrements in mobility and work capacity, patient out-of-pocket expenses for VLU care, and the adverse psychological toll of VLUs. ${ }^{8}$ Given the increasingly aging U.S. population, ${ }^{9}$ VLU rates and costs are likely to escalate over the next several decades.

Compression therapy has remained the standard VLU treatment for more than 30 years. ${ }^{10,11}$ Unfortunately, compression therapy confers only a moderate benefit: $50 \%-65 \%$ of VLUs are completely healed at 6 months; ${ }^{12-14} 20 \%$ remain unhealed at 2 years; ${ }^{5}$ and approximately $8 \%$ remain unhealed at 5 years. ${ }^{5}$ These poor healing rates may be due to the inadequacy of compression therapy to address the complex pathophysiological mechanisms responsible for the development and chronicity of VLUs, which include valvular insufficiency with subsequent venous hypertension, multiple changes occurring at the cellular and capillary level, and an insufficient wound matrix that does not allow for normal migration and proliferation of regenerating cells. ${ }^{15-17}$

VLU-related treatment costs are directly related to time to achieve complete wound closure. A retrospective analysis of the medical records of 78 patients (mean age of 67 years) who were treated in 1995 for VLUs followed patients until they achieved complete wound closure or to 1 year, whichever occurred first. ${ }^{7}$ The mean cost per VLU treatment episode was $\$ 9,685$ in 1997 U.S. dollars (USD; inflated to $\$ 16,524$ in 2011 USD using the Consumer Price Index for Medical Care $[\mathrm{CPI}-\mathrm{MC}])^{18}$ with an average monthly cost of $\$ 2,400(\$ 4,095$ in 2011 USD). Although most patients with VLUs received only outpatient care, the minority who required hospitalization and home health visits accounted for $25 \%$ and $48 \%$, respectively, of VLU-related direct costs. ${ }^{7}$ Average total direct costs (2011 USD) incurred during 3-month follow-up intervals were similar over the first 9 months of treatment $(\$ 5,736$ during months $0-3$; $\$ 5,088$ during months $4-6$; and $\$ 5,108$ during months $7-9)$, suggesting that reductions in ulcer closure time could substantially decrease VLU-related costs. In a review of VLUrelated cost studies conducted by Kurz et al. (1999), investigators noted that although the cost to achieve VLU closure at 12 weeks was approximately \$1,357 (updated from 1991 to 2011
USD using the CPI-MC), costs approached $\$ 30,765$ (updated from 1987 to 2011 CPI-MC-adjusted USD) for ulcers requiring more than 12 weeks of care. ${ }^{3}$

Guidance provided by the U.S. Food and Drug Administration (FDA) notes that the most clinically meaningful endpoint for Phase 3 clinical trials of wound healing treatments is the percentage of patients who achieve complete wound closure, defined as skin re-epithelialization without drainage or dressing requirements confirmed at 2 consecutive study visits 2 weeks apart, within a specified period of time. ${ }^{19}$ Whereas measures of partial wound healing may suggest early treatment response, ${ }^{20} \mathrm{FDA}$ guidance suggests that these measures should not be used as primary endpoints in Phase 3 clinical trials because the clinical benefit of incremental wound size changes has not been established. ${ }^{19}$

Research has demonstrated the promising efficacy of several advanced wound care matrices (AWCMs) for the treatment of VLUs as adjuncts to compression therapy.12,21,22 The term "advanced wound care matrix" is used to characterize a heterogeneous group of cellular (living cells) or acellular (biologically inert) products derived from biological (animal, human, or plant), synthetic, or composite (combined) sources. Although their modes of action are not fully understood and appear to vary by product, healing effects of AWCMs may include increased cell proliferation and migration, accelerated angiogenesis, augmented pro-inflammatory cytokine and growth factor production, inactivation of damaging proteases, and reduced bacterial burden..$^{23-30}$

The conditions for initiating adjunctive treatment with AWCMs have not been definitively established. Margolis et al. (2004) suggested that such advanced therapies are appropriate as part of the initial treatment regimen in VLU patients with poor prognostic indicators (those with VLUs of 10 or more squared centimeters $\left[\mathrm{cm}^{2}\right]$, VLU duration of 1 year or more, peripheral artery disease, or more than $50 \%$ of the ulcer consisting of fibrous connective tissue). ${ }^{31}$ Warriner (2010) proposed the use of AWCMs as a subsequent add-on to compression therapy in patients whose VLU size has not been reduced by at least $30 \%$ over the first 4 weeks of compression therapy. ${ }^{32}$

In general, commercial plans provide coverage and reimbursement for AWCMs in patients with VLUs that have failed to adequately respond to at least 1 month of treatment with compression therapy alone. ${ }^{33,34}$ Medicare does not provide a national coverage determination for the use of AWCMs. Examples of criteria for local coverage determinations (LCDs) include venous ulcers of greater than 3 months' duration that have failed to respond to documented conservative measures for more than 2 months (Wisconsin Physicians 2012) ) $^{35}$ and venous ulcers that have failed to respond, defined as ulcers that have increased in size or depth or for which there has been less than 30\% closure from baseline (TrailBlazer Health Enterprises 2012), after 4 weeks of conservative treatment. ${ }^{36}$ Some LCDs 
limit Medicare payment to 5 applications per ulcer episode for Apligraf and to 12 applications per ulcer episode for Oasis. ${ }^{36,37}$

Given the anticipated increase in rates of VLUs and the high costs of VLU-related care, health plans must carefully assess the comparative value of adjuncts to compression therapy for the treatment of chronic VLUs. We present one such method that calculates the number needed to treat (NNT) to model the comparative clinical and cost efficacy of AWCMs currently available as adjuncts to compression therapy for the treatment of VLUs in the United States from the health care system (payer) perspective.

\section{Methods}

\section{Model Overview}

The target population for the NNT calculation was communitydwelling patients with VLUs of more than 4 weeks duration treated in an outpatient setting over a treatment period of up to 24 weeks. Given the short time horizon, costs were not discounted. For each targeted AWCM used adjunctively with compression therapy, the model addressed the following questions:

(a) How many additional patients must receive the targeted therapy for up to 24 weeks to achieve 1 additional patient "success" (i.e., complete wound closure) over that which is achieved with compression therapy alone?

(b)What is the incremental cost to achieve this additional patient success?

\section{Model Parameters}

Clinical parameters and related sources of information for the model are described below.

1. Efficacy, defined as the percentage of patients achieving complete wound closure (i.e., full epithelialization of the wound and the complete absence of drainage from the wound site) within 24 weeks of treatment initiation among intent-to-treat study populations, was obtained from a review of published randomized controlled trials (RCTs).

2. The average number of applications of each AWCM to achieve complete wound closure within 24 weeks was obtained from the published articles of Apligraf ${ }^{12}$ and $\mathrm{Oasis}^{20}$ and from the principal investigator of the Talymed study.

3. Sheet size of each targeted AWCM was obtained from manufacturers' websites.

4. Average wound sizes $\left(\mathrm{cm}^{2}\right)$ at baseline were assumed to equal those measured in the source RCTs $-1 \mathrm{~cm}^{2}$ for Apligraf, ${ }^{12}$ $10-12 \mathrm{~cm}^{2}$ for Oasis, ${ }^{20}$ and $10-13 \mathrm{~cm}^{2}$ for Talymed. ${ }^{21}$

5. Based on the sheet size of each targeted AWCM, the average wound sizes reported in the source RCTs, and the requirement that a new AWCM sheet be used at every treatment application visit, 1 entire sheet would be required to sufficiently cover and treat each VLU.

The costs per sheet of Apligraf and Oasis were based on wholesale acquisition costs (WAC) obtained from published
September 2011 drug pricing according to Red Book. ${ }^{38}$ Because Red Book did not provide the WAC price for Talymed, this information was obtained from the manufacturer.

\section{Literature Review}

A review of the literature was conducted to identify RCTs that evaluated the efficacy of AWCMs approved or cleared by the FDA for the treatment of VLUs as of September 2011. These products included Apligraf (previously Graftskin), EndoForm Dermal Template, Hyalomatrix, Integra Matrix Wound Dressing, Jaloskin, MatriStem Wound Matrix, Oasis Wound Matrix, PriMatrix, Promogran, Talymed, and Theraskin. (We note that Shire, PLC, discontinued pursuit of a VLU indication for Dermagraft, a fibroblast-derived skin substitute indicated for diabetic ulcers, following preliminary analyses of the data from a pivotal Phase 3 trial. ( $^{39}$ Therefore, studies of this product (and others not cleared or approved for the treatment of VLUs) were excluded from our analyses. Based on FDA guidance previously noted, only studies that reported the percentage of patients achieving complete wound closure within 24 weeks, or studies from which this information could be calculated, were included.

Figure 1 summarizes the methods to identify studies for inclusion in our analysis. We first conducted a Medline search using the following MeSH terms: "Leg Ulcer/therapy" and ("Skin, Artificial" or "Biological Dressings" or "Collagen" or "Keratinocytes"). This search, which was limited to RCTs and English-language articles published from the earliest available publication dates to June 1, 2011, identified 38 publications. Next, to ensure that we did not omit eligible studies that were not indexed in Medline, we examined citations listed in the reimbursement policy reviews for bioengineered skin substitutes published online by 2 large representative health plans $s^{33,34}$ and conducted a manual search of references cited in relevant identified publications. The health plan policies were reviewed because there were no recently published systematic literature reviews of AWCMs for the treatment of VLUs. The search of the 2 health plan policies identified 77 additional references, 17 of which were cited by both sources, resulting in a total of 60 additional unique references. The hand search identified 6 more relevant publications.

These 3 search methods resulted in the identification of 104 unique references, which were examined to determine their eligibility for inclusion in the analysis. Of the 104 references, 100 were excluded for the following reasons:

- 24 were not RCTs.

o 21 were review articles.

o 1 was a case study.

o 1 was a retrospective, uncontrolled study of Theraskin.

o 1 study of Promogran allowed patients to cross over to the active or control group prior to assessing complete wound closure. 


\section{FIGURE 1 Identification of Studies for Inclusion in NNT Calculation}

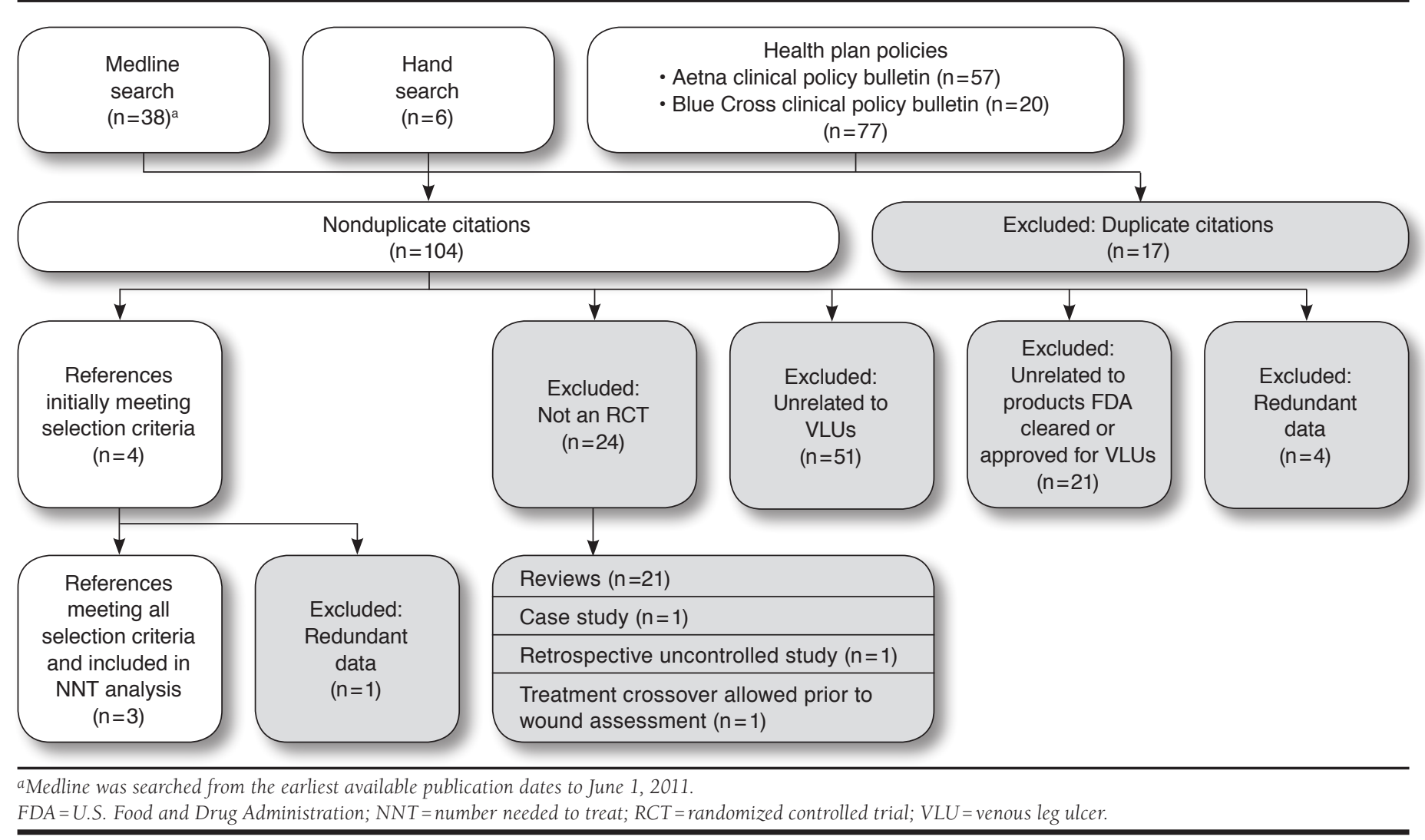

- 51 examined the treatment of wounds other than VLUs (diabetic ulcers, burns, mixed etiology ulcers, and surgical wounds).

- 21 did not pertain to AWCMs approved or cleared by the FDA for the treatment of VLUs.

- 4 reported redundant data from other studies.

Four references (reporting data from 3 studies) initially met all criteria for inclusion in the analysis: 2 pertained to Apligraf (Oganogenesis, Inc; Canton, MA); ;2,40 1 pertained to Oasis Wound Matrix (Healthpoint Biotherapeutics; San Antonio, TX) ${ }^{21,41}$ and 1 pertained to Talymed (Marine Polymer Technologies, Inc.; Danvers, MA).42 Because different sample sizes were used for the same study described in the Apligraf product insert ${ }^{40}$ and a published article, ${ }^{12}$ and we could find no means of reconciling this discrepancy, we excluded the Apligraf article ${ }^{12}$ and relied exclusively upon study methods and outcomes reported in the product insert. ${ }^{40}$ We note that this information is identical to that reported in the Apligraf FDA Summary of Safety and Effectiveness. ${ }^{43}$

Selection of Analyses for NNT Calculations. The Apligraf product insert analyzed and reported results from a single study comparing 24-week wound closure rates between Apligraf plus compression therapy versus compression therapy alone using 2 analyses. ${ }^{40}$ The first was an unadjusted comparison of the percentages of patients who achieved complete wound closure at 24 weeks (55.4\% in the Apligraf plus compression therapy group versus $49.1 \%$ in the compression therapy group; $P=0.365$ ). The second analysis, which adjusted for treatment center, baseline ulcer duration, and wound size, found a significant effect for Apligraf (complete wound closure at 24 weeks: Apligraf plus compression therapy $56.8 \%$ vs. compression therapy alone $39.8 \%, P=0.022$ ). Because only the adjusted analysis resulted in a significant effect for Apligraf, we calculated the NNT estimate based on these adjusted complete wound closure rates.

The Talymed study compared 3 active treatment regimens (applied only once, applied every 3 weeks, and applied biweekly) with adjunctive compression therapy to an arm that received compression therapy alone. ${ }^{22}$ The group that received biweekly Talymed had the highest wound closure rate, which was statistically significant compared with the control group; closure rates in the other active treatment arms were not statistically significantly different from that of the control group. 
Because this dose-ranging study was conducted to establish the most efficacious treatment regimen for Talymed in patients with VLUs, we calculated the NNT estimate based on the complete wound closure rate reported for the biweekly treatment arm.

\section{Product Descriptions}

Apligraf, approved in 1998 for use with compression therapy for the treatment of noninfected partial- and full-thickness VLUs of greater than 1 month duration that have not adequately responded to conventional ulcer therapy, is a living, bi-layered skin substitute consisting of a dermal layer of human foreskin-derived neonatal fibroblasts in a bovine type 1 collagen matrix and an epidermal layer of human foreskinderived neonatal keratinocytes. ${ }^{40}$ Oasis, cleared in 2006 for the management of wounds (including partial- and full-thickness wounds; pressure ulcers; venous ulcers; diabetic ulcers; chronic vascular ulcers; tunneled/undermined wounds; surgical wounds [donor sites/grafts, post-Moh's surgery, post-laser surgery, podiatric, and wound dehiscence]; trauma wounds [abrasions, lacerations, second-degree burns, and skin tears]; and draining wounds ${ }^{41}$ is an acellular collagen-based matrix derived from porcine small intestinal submucosa. ${ }^{21}$ Talymed, a biodegradable, wafer-thin wound matrix composed of shortened fibers of poly-N-acetyl glucosamine isolated from microalgae, ${ }^{22}$ was cleared in 2010 for management of diabetic ulcers; venous ulcers; pressure wounds; ulcers caused by mixed vascular etiologies; full-thickness and partial-thickness wounds; second-degree burns; surgical wounds-donor sites/grafts, postMoh's surgery, post-laser surgery, and other bleeding surface wounds; abrasions and lacerations; traumatic wounds healing by secondary intention; chronic vascular ulcers; and dehisced surgical wounds. ${ }^{42}$

\section{Calculation of NNT}

The NNT is a single, treatment-specific metric that characterizes relative efficacy in terms of the number of patients that must receive one treatment (Treatment A) over a specific period to achieve clinical benefit, compared with the number of patients that must receive another treatment (Treatment B) over the same time period. Patients receiving Treatment A are often presented as the active treatment group and those receiving Treatment B as the control or placebo group. ${ }^{44}$ An NNT of 1 represents a "perfect" outcome, in which all patients who receive the active treatment will achieve clinical benefit compared with the control. NNT is especially useful when comparing an outcome across a range of treatments among patients with similar conditions, as a treatment with a smaller NNT (i.e., closest to 1) is considered more efficacious than one with a larger NNT. ${ }^{44}$ The NNT point estimate is calculated as the inverse of the event rate (number of patients achieving benefit with treatment divided by total number of patients receiving treatment) for the active treatment group minus the event rate for the control group. ${ }^{44}$ We applied methods provided by Cook and Sackett $(1995)^{45}$ to calculate NNT point estimates and the Wilson score method, as described by Bender (2001) ${ }^{46}$ and Newcombe (1998), ${ }^{47}$ to calculate $95 \%$ confidence intervals (CIs) for each of the targeted AWCMs.

\section{Calculation of Incremental Cost Per Additional Successfully Treated Patient}

The following describes our methods for calculating the incremental cost per additional successfully treated patient.

- Based on the assumed wound sizes of $1 \mathrm{~cm}^{2}, 10-12 \mathrm{~cm}^{2}$, and $10-13 \mathrm{~cm}^{2}$ and sheet sizes of $44 \mathrm{~cm}^{2}, 25 \mathrm{~cm}^{2}$, and $21 \mathrm{~cm}^{2}$ for Apligraf, Oasis, and Talymed, respectively, we determined that a single sheet was sufficient to cover each VLU.

- Because any unused portion ("wastage") of these ACWMs cannot be reused, a new sheet was required for each reapplication of each product.

- We determined the WAC price per sheet/application of each product.

- We assumed that each VLU treatment episode would require the average number of applications received in each study: 3 applications for Apligraf, 8 for Oasis, and 8 for Talymed.

- To calculate the cost per VLU treatment episode for each product, we multiplied the number of sheets required for each application (1 for each product) by the WAC price per sheet and the average number of applications.

- To calculate incremental cost per additional successfully treated patient, we multiplied the point estimate NNT associated with each AWCM by the cost per VLU treatment episode.

- Similar calculations using the lower and upper NNT estimates were made to derive the $95 \%$ CIs for the incremental cost per additional successfully treated patient.

- In all 3 studies, the incidence of treatment-related adverse effects was similar in the active treatment and control groups. Therefore, the cost of adverse events was not included in the cost-efficacy analyses.

\section{Results}

\section{Description of Studies}

In all 3 studies, investigators reported the percentage of patients achieving complete wound closure within a specific duration of 12 to 24 weeks and defined "complete wound closure" as the full epithelialization of the wound and the complete absence of drainage from the wound site. Table 1 provides an overview of the 3 studies, which includes study design, comparators, number of subjects in each arm, active treatment regimen, maximum number of active treatment applications allowed per the study protocol, wound inclusion criteria, and excluded medical conditions.

Table 2 summarizes the baseline characteristics of patients in the 3 studies..$^{12,21,22,40,43}$ Studies were not comparable with 
Clinical and Cost Efficacy of Advanced Wound Care Matrices for Venous Ulcers

\section{TABLE 1 Overview of RCTs Used in NNT Calculations}

\begin{tabular}{|c|c|c|c|c|c|c|}
\hline \multirow[b]{2}{*}{ Interventions } & \multicolumn{2}{|c|}{ Apligraf 40} & \multicolumn{2}{|c|}{ Oasis 21} & \multicolumn{2}{|c|}{ Talymed $^{22}$} \\
\hline & Active & Control & Active & Control & Active & Control \\
\hline Design & \multicolumn{2}{|c|}{$\begin{array}{l}\text { Randomized, controlled, multicenter, } \\
\text { assessor nonblinded }\end{array}$} & \multicolumn{2}{|c|}{$\begin{array}{l}\text { Randomized, controlled, multicenter, } \\
\text { assessor nonblinded }\end{array}$} & \multicolumn{2}{|c|}{$\begin{array}{l}\text { Randomized, controlled, multicenter, } \\
\text { assessor-blinded }\end{array}$} \\
\hline Comparators & Apligraf $+\mathrm{CT}^{\mathrm{a}}$ & $\mathrm{CT}^{\mathrm{a}}$ & Oasis + CTa & $\mathrm{CT}^{\mathrm{a}}$ & Talymed + CTa & $\mathrm{CT}^{\mathrm{a}}$ \\
\hline Number of subjects per arm & 130 & 110 & 62 & 58 & 22 & 20 \\
\hline Active treatment regimen & \multicolumn{2}{|c|}{ Visit days $0,3-5,7,14$, and $21^{\mathrm{b}}$} & \multicolumn{2}{|c|}{ Weekly from day 0 through week 12} & \multicolumn{2}{|c|}{ Biweekly from day 0 through week 20} \\
\hline $\begin{array}{l}\text { Maximum number of active } \\
\text { treatment applications }\end{array}$ & \multicolumn{2}{|c|}{5} & \multicolumn{2}{|c|}{12} & \multicolumn{2}{|c|}{10} \\
\hline \multicolumn{7}{|l|}{ Inclusion criteria } \\
\hline Venous ulcer/insufficiency & \multicolumn{2}{|c|}{ All subjects } & \multicolumn{2}{|c|}{ All subjects } & \multicolumn{2}{|c|}{ All subjects } \\
\hline Ulcer duration & \multicolumn{2}{|c|}{$>4$ weeks } & \multicolumn{2}{|c|}{$>4$ weeks } & \multicolumn{2}{|c|}{$>4$ weeks and $<6$ months } \\
\hline Ulcer size $\left(\mathrm{cm}^{2}\right)$ & \multicolumn{2}{|c|}{ Not specified } & \multicolumn{2}{|c|}{$1-64$} & \multicolumn{2}{|c|}{$2-20$} \\
\hline $\begin{array}{l}\text { No cellulitis/necrosis/exposed } \\
\text { bone or fascia }\end{array}$ & \multicolumn{2}{|c|}{ All subjects } & \multicolumn{2}{|c|}{ All subjects } & \multicolumn{2}{|c|}{ All subjects } \\
\hline $\begin{array}{l}\text { Viable wound bed with } \\
\text { granulation tissue }\end{array}$ & \multicolumn{2}{|c|}{ Not specified } & \multicolumn{2}{|c|}{ All subjects } & \multicolumn{2}{|c|}{ All subjects } \\
\hline \multicolumn{7}{|l|}{ Exclusion criteria } \\
\hline Peripheral artery disease & \multicolumn{2}{|c|}{ Stated as exclusion criterion } & \multicolumn{2}{|c|}{ Stated as exclusion criterion } & Stated as ex & criterion \\
\hline Collagen vascular disease & Stated as exc & criterion & Stated as e: & criterion & Stated as ex & criterion \\
\hline Active wound/systemic infection & Stated as exc & criterion & Stated as e: & criterion & Stated as ex & criterion \\
\hline Previous radiation therapy & Stated as exc & criterion & Stated as e: & criterion & Stated as ex & criterion \\
\hline Hemodialysis or renal disease & Stated as ex & a criterion & Stated as e: & criterion & Stated as ex & criterion \\
\hline Uncontrolled diabetes & Stated as exc & criterion & Stated as e: & criterion & Not stated as e & on criterion \\
\hline Rheumatoid arthritis & Stated as exc & criterion & Stated as e: & criterion & Not stated ase & on criterion \\
\hline $\begin{array}{l}\text { Corticosteroids/ } \\
\text { immunosuppressants }\end{array}$ & Stated as ex & n criterion & Stated as e: & criterion & Not stated as e & on criterion \\
\hline Organ transplantation & Not stated as e & ion criterion & Stated as e: & criterion & Stated as ex & criterion \\
\hline Active sickle cell disease & Not stated as e & ion criterion & Stated as e: & criterion & Stated as ex & c criterion \\
\hline Congestive heart failure & Not stated as e & ion criterion & Stated as e: & criterion & Not stated ase & on criterion \\
\hline Malnutrition & Not stated as e & ion criterion & Stated as e: & criterion & Stated as ex & criterion \\
\hline Charcot's disease & Not stated as e & ion criterion & Not stated as & on criterion & Stated as ex & criterion \\
\hline
\end{tabular}

respect to baseline wound characteristics. The average ulcer size at baseline was $1 \mathrm{~cm}^{2}$ in the Apligraf study ${ }^{12}$ compared with $10-12 \mathrm{~cm}^{2}$ and $10-13 \mathrm{~cm}^{2}$ in the Oasis ${ }^{21}$ and Talymed ${ }^{22}$ studies, respectively. In the Apligraf study, 50\% of patients had ulcer durations of 1 year or more, and 69\% had ulcer durations of 6 months or more. ${ }^{12}$ In the Oasis study, 37\% of patients had ulcer durations exceeding 1 year; $47 \%$ had ulcer durations of 7 months or more; and 63\% had ulcer durations of 4 months or more. ${ }^{21}$ In contrast, the Talymed study protocol excluded patients with ulcer durations exceeding 6 months, and the average ulcer duration in the Talymed study was 3.2 months. ${ }^{22}$

\section{Clinical Efficacy and Safety}

Table 3 presents the complete wound closure rates, NNT point estimates, and $95 \%$ CIs for each comparison of active treatment plus compression therapy versus compression therapy alone. NNT point estimates were 2 for Talymed, 5 for Oasis, and 6 for
Apligraf; 95\% CIs ranged from 2 to 8 for Talymed, 3 to 24 for Apligraf, and 3 to 39 for Oasis.

\section{Cost Efficacy}

Table 4 presents the efficacy and cost variables used to determine the incremental cost to achieve 1 additional successfully treated patient associated with each targeted AWCM. Estimated costs per VLU patient treated were $\$ 4,992$ for Apligraf, $\$ 800$ for Talymed, and $\$ 630$ for Oasis. We multiplied the cost of an episode of therapy with each treatment by the NNT point estimate to derive the incremental cost to achieve an additional successfully treated patient over that achieved with compression therapy alone. The point estimate $(95 \%$ CI) incremental costs to achieve an additional successfully treated patient were $\$ 1,600$ ( $\$ 1,600-\$ 6,400)$ for Talymed, $\$ 3,150$ (\$1,890-\$24,570) for Oasis, and \$29,952 (\$14,976-\$119,808) for Apligraf. 


\section{TABLE 2}

\begin{tabular}{|c|c|c|c|c|c|c|}
\hline \multirow[b]{2}{*}{ Characteristic } & \multicolumn{2}{|c|}{ Apligraf 40} & \multicolumn{2}{|c|}{ Oasis $^{21}$} & \multicolumn{2}{|c|}{ Talymed $^{22}$} \\
\hline & $\begin{array}{c}\text { Active } \\
(\mathrm{n}=130)\end{array}$ & $\begin{array}{l}\text { Control } \\
(\mathrm{n}=110)\end{array}$ & $\begin{array}{l}\text { Active } \\
(\mathrm{n}=62)\end{array}$ & $\begin{array}{l}\text { Control } \\
(\mathrm{n}=58)\end{array}$ & $\begin{array}{l}\text { Active } \\
(\mathbf{n}=22)\end{array}$ & $\begin{array}{l}\text { Control } \\
(\mathrm{n}=20)\end{array}$ \\
\hline $\begin{array}{l}\text { Age (years), } \\
\text { mean [SD] }\end{array}$ & \multicolumn{2}{|c|}{ Not provided } & $\begin{array}{l}63 \\
{[2]^{\mathrm{b}}}\end{array}$ & $\begin{array}{l}65 \\
{[2]^{b}}\end{array}$ & $\begin{array}{c}63 \\
{[15]}\end{array}$ & $\begin{array}{c}63 \\
{[15]}\end{array}$ \\
\hline $\begin{array}{l}\text { Female, } \\
\%(\mathrm{n})\end{array}$ & $\begin{array}{l}46.2 \\
(60) \\
\end{array}$ & $\begin{array}{l}52.7 \\
(58) \\
\end{array}$ & $\begin{array}{l}53.2 \\
(33)\end{array}$ & $\begin{array}{l}63.8 \\
(37) \\
\end{array}$ & $\begin{array}{c}40.9 \\
(9)\end{array}$ & $\begin{array}{l}50.0 \\
(10) \\
\end{array}$ \\
\hline $\begin{array}{l}\text { Ulcer size }\left(\mathrm{cm}^{2}\right) \text {, } \\
\text { mean }[\mathrm{SD}]\end{array}$ & \begin{tabular}{c|}
1.33 \\
{$[2.69]^{\mathrm{c}}$}
\end{tabular} & $\begin{array}{l}1.05 \\
{[1.61]^{\mathrm{c}}}\end{array}$ & $\begin{array}{l}10.2 \\
{[1.5]}\end{array}$ & $\begin{array}{l}12.1 \\
{[2.0]}\end{array}$ & $\begin{array}{c}9.8 \\
{[7.3]}\end{array}$ & $\begin{array}{l}12.8 \\
{[12.0]}\end{array}$ \\
\hline $\begin{array}{l}\text { Ulcer duration } \\
\text { more than } 1 \\
\text { year, \% (n) }\end{array}$ & $\begin{array}{l}55.4 \\
(72)\end{array}$ & $\begin{array}{l}43.6 \\
(48)\end{array}$ & $\begin{array}{l}33.9 \\
(21)\end{array}$ & $\begin{array}{l}39.7 \\
(23)\end{array}$ & $\begin{array}{l}0.0 \\
(0)^{d}\end{array}$ & $\begin{array}{l}0.0 \\
(0)^{\mathrm{d}}\end{array}$ \\
\hline
\end{tabular}

an all 3 studies, there were no statistically significant between-group differences in measured baseline characteristics.

${ }^{b}$ Mean age reported with standard error of the mean rather than $S D$.

'Average ulcer sizes for Apligraf groups were not provided in the product insert; these were obtained from the Apligraf article, which used a somewhat different sample derived from the same study. ${ }^{12}$

dPatients with VLU duration of more than 6 months were excluded. Mean [SD] ulcer duration: 3.6 [1.8] months in active treatment, 2.7 [1.6] months in control group, and 3.2 [1.8] months overall.

$\mathrm{cm}^{2}=$ squared centimeters; $S D=$ standard deviation; $V L U=$ venous leg ulcers.

\section{TABLE 3 NNT to Achieve 1 Additional Patient} with Complete Wound Closure in Patients Receiving Advanced Wound Care Matrix Therapy Plus Compression Therapy Versus Compression Therapy Alone

\begin{tabular}{|c|c|c|c|c|c|}
\hline & $\begin{array}{c}\mathrm{N} \\
\text { Per Arm }\end{array}$ & $\begin{array}{c}\text { Complete } \\
\text { Wound } \\
\text { Closure, } \\
\%(n)\end{array}$ & NNT & $\begin{array}{c}95 \% \\
\text { CI }\end{array}$ & $\begin{array}{c}P \\
\text { Value }\end{array}$ \\
\hline $\begin{array}{l}\text { Apligraf @24 weeks } \\
\text { (adjusteda)40 }\end{array}$ & 130 & $\begin{array}{c}56.8 \% \\
(74)\end{array}$ & \multirow[t]{2}{*}{6} & \multirow[t]{2}{*}{3 to 24} & \multirow[t]{2}{*}{0.022} \\
\hline $\begin{array}{l}\text { Compression therapy @ } \\
24 \text { weeks (adjusteda)40 }\end{array}$ & 110 & $\begin{array}{c}39.8 \% \\
(44)\end{array}$ & & & \\
\hline Oasis@12 weeks ${ }^{21}$ & 62 & $\begin{array}{l}54.8 \% \\
(34)\end{array}$ & \multirow[t]{2}{*}{5} & \multirow[t]{2}{*}{3 to 39} & \multirow[t]{2}{*}{0.020} \\
\hline $\begin{array}{l}\text { Compression therapy@ } \\
12 \text { weeks }{ }^{21}\end{array}$ & 58 & $\begin{array}{c}34.5 \% \\
(20)\end{array}$ & & & \\
\hline Talymed@20 weeks²2 & 22 & $\begin{array}{l}86.4 \% \\
(19)\end{array}$ & \multirow[t]{2}{*}{2} & \multirow[t]{2}{*}{2 to 8} & \multirow[t]{2}{*}{0.005} \\
\hline $\begin{array}{l}\text { Compression therapy @ } \\
20 \text { weeks } 22\end{array}$ & 20 & $\begin{array}{l}45.0 \% \\
(9)\end{array}$ & & & \\
\hline
\end{tabular}

${ }^{a}$ Adjusted for study center, baseline ulcer duration, and baseline wound size. $C I=$ confidence interval; $N N T=$ number needed to treat.

to evaluate whether identifying such high-risk patients, and providing them with early adjunctive treatment with AWCMs, is a cost-effective strategy.

\section{Limitations}

Several limitations to this study are noted. First, treatment outcomes were assessed across different periods: 12 weeks for Oasis, 20 weeks for Talymed, and 24 weeks for Apligraf. Comparison of NNTs across clinical trials of different durations is generally not advised: NNT may decrease with longer study durations as events accrue and the absolute event rate increases. ${ }^{49}$ This suggests the possibility that Oasis, which had the shortest trial duration (12 weeks), may have been disadvantaged relative to Talymed (duration of 20 weeks) and Apligraf (duration of 24 weeks). Unfortunately, it is not known if improved outcomes (i.e., higher wound closure rates) would be achievable with a longer duration of treatment for any of these products.

Second, baseline wound characteristics were not comparable across the 3 RCTs. One notable difference was the mean baseline size of ulcers; the average ulcer size was $1 \mathrm{~cm}^{2}$ in the Apligraf study compared with $10-12 \mathrm{~cm}^{2}$ and $10-13 \mathrm{~cm}^{2}$ for the Oasis and Talymed studies, respectively. In addition, the duration of ulcers differed markedly across studies. Ulcer durations exceeded 12 months for 50\% of patients in the Apligraf study and were 7 months or more for $47 \%$ of patients in the Oasis study. In contrast, patients with ulcer durations exceeding 6 months were excluded from the study of Talymed. Research 


\section{TABLE 4 Model Parameters and Outcomes}

\begin{tabular}{|c|c|c|c|c|}
\hline & \multirow{2}{*}{$\begin{array}{c}\begin{array}{c}\text { Apligraf } \\
\text { (adjusted }^{a} \text { ) }\end{array} \\
24 \text { weeks }\end{array}$} & \multirow{2}{*}{$\begin{array}{c}\text { Oasis } \\
12 \text { weeks }\end{array}$} & \multirow{2}{*}{$\begin{array}{c}\text { Talymed } \\
20 \text { weeks }\end{array}$} \\
\hline & & & & \\
\hline$A$ & NNT point estimate & 6 & 5 & 2 \\
\hline B & NNT lower 95\% CI limit & 3 & 3 & 2 \\
\hline $\mathrm{C}$ & NNT upper 95\% CI limit & 24 & 39 & 8 \\
\hline $\mathrm{D}$ & Average wound size $\left(\mathrm{cm}^{2}\right)$ & 1 & $10-12$ & $10-13$ \\
\hline $\mathrm{E}$ & Sheet size $\left(\mathrm{cm}^{2}\right)^{\mathrm{b}}$ & 44 & 21 & 25 \\
\hline $\mathbf{F}$ & $\begin{array}{l}\text { Number of sheets required per } \\
\text { applicationc }\end{array}$ & 1 & 1 & 1 \\
\hline $\mathrm{G}$ & Cost per sheet (WAC)d & $\$ 1,664.00$ & $\$ 78.75$ & $\$ 100.00$ \\
\hline $\mathrm{H}$ & $\begin{array}{l}\text { Average number of sheets used } \\
\text { per VLU episode }\end{array}$ & 3 & 8 & 8 \\
\hline $\mathrm{I}$ & $\begin{array}{l}\text { Cost per patient VLU } \\
\text { episode }(F \times G \times H)\end{array}$ & $\$ 4,992$ & $\$ 630$ & $\$ 800$ \\
\hline $\mathrm{J}$ & Cost per NNT point estimate $(\mathrm{A} \times \mathrm{I})$ & $\$ 29,952$ & $\$ 3,150$ & $\$ 1,600$ \\
\hline $\mathrm{K}$ & Cost per $95 \%$ CI lower limit $(B \times I)$ & $\$ 14,976$ & $\$ 1,890$ & $\$ 1,600$ \\
\hline $\mathrm{L}$ & Cost per 95\% CI upper limit $(\mathrm{C} \times \mathrm{I})$ & $\$ 119,808$ & $\$ 24,570$ & $\$ 6,400$ \\
\hline \multicolumn{5}{|c|}{$\begin{array}{l}\text { ¿Costs (WAC) per sheet for Apligraf and Oasis were obtained from published } \\
\text { September } 2011 \text { drug pricing according to Red Book } 38 \text { and from the manufacturer } \\
\text { of Talymed. } \\
\text { 'We assumed that each VLU episode would require the average number of sheets/ } \\
\text { applications used as specified in each study. } \\
C I=\text { confidence interval; } \mathrm{cm}^{2}=\text { squared centimeters; NNT = number needed to treat; } \\
V L U=\text { venous leg ulcer; WAC = wholesale acquisition cost. }\end{array}$} \\
\hline
\end{tabular}

has shown that smaller ulcer size (less than 5 squared centimeters, ${ }^{50,51}$ less than 10 squared centimeters, ${ }^{31,52}$ less than 20 squared centimeters ${ }^{53}$ ) and shorter ulcer duration (less than 3 months, ${ }^{52}$ less than 6 months, ${ }^{50}$ less than 1 year ${ }^{31,51,53}$ ) predict increased likelihood of complete wound closure. In a multinational survey of more than 1,000 physicians, $67.9 \%$ and $72.5 \%$, respectively, considered a VLU exceeding $5 \mathrm{~cm}^{2}$ in size and duration of more than 3 months as strong indicators of hard-toheal VLUs. ${ }^{54}$ Therefore, our NNT calculations for Apligraf may only apply to smaller but more long-standing VLUs, and it is unknown whether the efficacy and NNT results for these products would change if calculated from samples of comparable wound severity. In addition, studies varied by baseline rates of comorbid illnesses, although all studies excluded patients with conditions that would be likely to impede wound healing.

Third, only 3 studies met criteria for inclusion in the analyses, and concerns about the quality of these studies have been noted. ${ }^{51}$ The Apligraf and Oasis studies were judged to have a high degree of bias per the quality assessment criteria applied in a 2011 technology assessment of skin substitutes for chronic wounds by the Agency for Healthcare Research and Quality (AHRQ), ${ }^{55}$ mainly due to the lack of blinding of the wound assessor. ${ }^{55} \mathrm{Had}$ the Apligraf and Oasis studies included a blinded assessor, the studies would have been considered to have a moderate and low degree of bias, respectively. The Talymed study, which was not included in the AHRQ review due to its later publication date, was the only one included in the present analysis to use blinded assessment of complete wound closure. ${ }^{22}$ However, because of its small sample size, the Talymed study was described by its authors as a pilot study that "should be replicated in a larger trial." 22 The AHRQ review mentioned additional quality limitations of skin substitute studies, including poor reporting of prior wound treatments and comorbidities. ${ }^{55} \mathrm{In}$ addition for calling for a greater number of high-quality RCTs of skin substitutes, AHRQ also noted the need for head-to-head comparisons of treatments and studies that include patients with medical conditions that might impede wound healing (e.g., uncontrolled diabetes and peripheral vascular disease). ${ }^{55}$

Fourth, we were unable to estimate total direct costs for the treatment of VLUs because these studies did not report health utilization outcomes. Although most patients with VLUs receive only outpatient care, the minority that require hospitalization and home health visits account for $25 \%$ and $48 \%$, respectively, of VLU-related direct costs. ${ }^{7}$ In general, speed of VLU healing is inversely associated with health care costs. Therefore, when all direct costs are considered, it is possible that some highly efficacious but expensive therapies could be more cost-effective in routine clinical practice than moderately efficacious but less expensive treatments. Prospective RCTs of VLU treatments that assess both efficacy and direct costs are needed to more fully define the potential benefits of AWCMs to payers.

Fifth, although the present study focuses on cost outcomes, it is important to consider the benefits of faster wound healing from the patient's perspective. Treatment with AWCMs may positively affect the quality of life of patients suffering from VLUs by expediting closure of the ulcers, ${ }^{56}$ preventing complications (e.g., cellulitis and osteomyelitis) associated with delayed ulcer healing, ${ }^{57}$ and decreasing the frequency of dressing changes.

\section{Conclusions}

This study constitutes the first comparison of clinical and cost efficacy of AWCMs among patients with VLUs. Analyses were based on the proportion of patients achieving complete wound closure, identified by the FDA as the most objective and clinically meaningful wound-healing endpoint, ${ }^{19}$ reported in RCTs based on intent-to-treat populations. Given escalating clinical demand and high cost of care for VLUs, as well as mounting economic constraints, there is a great need for more highquality clinical trials, including head-to-head comparisons of AWCMs to assist payers in evaluating the relative value of these treatments in terms of both clinical efficacy and incremental cost per successful wound closure. In addition, studies of the effectiveness of these treatments in clinical practice settings would also contribute to our understanding of the benefits of the treatments in "real-world" settings. 


\section{Authors}

CHERYL S. HANKIN, PhD, is President and Chief Scientific Officer, and AMY BRONSTONE, PhD, is Director of Medical Writing, BioMedEcon, LLC, Moss Beach, California. JOHN KNISPEL, MD, is Principal, Knispel Associates, Singer Island, Florida. MARIA LOPES, MD, is President, MMD Lopes, LLC, Cresskill, New Jersey. ERIK MAUS, MD, is Assistant Professor, University of Texas Medical School at Houston, Houston, Texas.

AUTHOR CORRESPONDENCE: Cheryl S. Hankin, PhD, President and Chief Scientific Officer, BioMedEcon, LLC, P.O. Box 129, Moss Beach, CA 94038. Tel.: 650.563.9475; Fax: 650.563.9485; E-mail: chankin@biomedecon.com.

\section{DISCLOSURES}

This study was funded by Marine Polymer Technologies, Inc., manufacturer of Talymed. Hankin and Bronstone are consultants who were paid by Marine Polymer Technologies to conduct this research and prepare this manuscript. The other 3 authors report no financial conflicts of interest.

Concept and design were performed by Hankin and Bronstone, with the assistance of Knispel and Lopes. Data were collected by Hankin and Bronstone, and were interpreted primarily by Hankin, Knispel, and Lopes, with the assistance of Bronstone and Maus. The manuscript was written by Bronstone and Hankin and revised primarily by Bronstone, with the assistance of the other authors.

\section{REFERENCES}

1. Phillips TJ, Dover JS. Leg ulcers. J Am Acad Dermatol. 1991;25(6 Pt 1):965-87. 2. Jones KR. Why do chronic venous leg ulcers not heal? J Nurs Care Qual. 2009;24(2):116-24; quiz 125-26

3. Kurz X, Kahn SR, Abenhaim L, et al. Chronic venous disorders of the leg: epidemiology, outcomes, diagnosis and management. Summary of an evidence-based report of the VEINES task force. Venous Insufficiency Epidemiologic and Economic Studies. Int Angiol. 1999;18(2):83-102.

4. Coon WW, Willis PW 3rd, Keller JB. Venous thromboembolism and other venous disease in the Tecumseh community health study. Circulation. 1973;48(4):839-46. Available at: http://circ.ahajournals.org/content/48/4/839.long. Accessed May 27, 2012.

5. Callam MJ, Harper DR, Dale JJ, Ruckley CV. Chronic ulcer of the leg: clinical history. Br Med J (Clin Res Ed). 1987;294(6584):1389-91. Available at: http://www.ncbi.nlm.nih.gov/pmc/articles/PMC1246555/pdf/bmjcred00022-0025.pdf. Accessed May 27, 2012.

6. Ongenae KC, Phillips TJ. Leg ulcer management. Emerg Med. 1993;25:45-53. 7. Olin JW, Beusterien KM, Childs MB, Seavey C, McHugh L, Griffiths RI. Medical costs of treating venous stasis ulcers: evidence from a retrospective cohort study. Vasc Med. 1999;4(1):1-7. Available at: http://vmj.sagepub.com/ content/4/1/1.full.pdf. Accessed May 27, 2012.

8. Phillips T, Stanton B, Provan A, Lew R. A study of the impact of leg ulcers on quality of life: financial, social, and psychologic implications. J Am Acad Dermatol. 1994;31(1):49-53.

9. Vincent GK, Velkoff VA. The next four decades: the older population in the United States: 2010 to 2050. Current Population Reports. P25-1138. U.S. Census Bureau. 2010. Available at: http://www.census.gov/prod/2010pubs/ p25-1138.pdf. Accessed May 27, 2012.

10. Wound Ostomy and Continence Nurses Society. Guideline for Management of Wounds in Patients with Lower-Extremity Venous Disease. Glenview, IL: Wound Ostomy and Continence Nurses Society (WOCN); 2005.
11. Robson MC, Cooper DM, Aslam R, et al. Guidelines for the treatment of venous ulcers. Wound Repair Regen. 2006;14(6):649-62.

12. Falanga V, Margolis D, Alvarez $\mathrm{O}$, et al. Rapid healing of venous ulcers and lack of clinical rejection with an allogeneic cultured human skin equivalent. Human Skin Equivalent Investigators Group. Arch Dermatol. 1998;134(3):293-300.

13. Polignano R, Bonadeo P, Gasbarro S, Allegra C. A randomised controlled study of four-layer compression versus Unna's Boot for venous ulcers. $J$ Wound Care. 2004;13(1):21-24.

14. Barwell JR, Davies CE, Deacon J, et al. Comparison of surgery and compression with compression alone in chronic venous ulceration (ESCHAR study): randomised controlled trial. Lancet. 2004;363(9424):1854-59.

15. Simka M. Cellular and molecular mechanisms of venous leg ulcers development—the "puzzle" theory. Int Angiol. 2010;29(1):1-19.

16. Loots MA, Lamme EN, Zeegelaar J, Mekkes JR, Bos JD, Middelkoop E. Differences in cellular infiltrate and extracellular matrix of chronic diabetic and venous ulcers versus acute wounds. J Invest Dermatol. 1998;111(5):850-57.

17. Herrick SE, Sloan P, McGurk M, Freak L, McCollum CN, Ferguson MW. Sequential changes in histologic pattern and extracellular matrix deposition during the healing of chronic venous ulcers. Am J Pathol. 1992;141(5):1085-95.

18. Bureau of Labor Statistics. Consumer price index. Available at: http:// data.bls.gov/cgi-bin/surveymost?cu. Accessed May 27, 2012.

19. U.S. Food and Drug Administration. Guidance for industry: chronic cutaneous ulcer and burn wounds-developing products for treatment. June 2006. Available at: http://www.fda.gov/downloads/Drugs/ GuidanceComplianceRegulatoryInformation/Guidances/ucm071324.pdf. Accessed May 27, 2012.

20. Gelfand JM, Hoffstad O, Margolis DJ. Surrogate endpoints for the treatment of venous leg ulcers. J Invest Dermatol. 2002;119(6):1420-25. Available at: http://www.nature.com/jid/journal/vl19/n6/pdf/5603355a.pdf. Accessed May 27, 2012.

21. Mostow EN, Haraway GD, Dalsing M, Hodde JP, King D. Effectiveness of an extracellular matrix graft (OASIS Wound Matrix) in the treatment of chronic leg ulcers: a randomized clinical trial. J Vasc Surg. 2005;41(5):83743. Available at: http://download.journals.elsevierhealth.com/pdfs/journals/0741-5214/PIIS0741521405001813.pdf. Accessed May 27, 2012.

22. Kelechi TJ, Mueller M, Hankin CS, Bronstone A, Samies J, Bonhan PA. A randomized, investigator-blinded, controlled pilot study to evaluate the safety and efficacy of a poly- $\mathrm{N}$-acetyl glucosamine-derived membrane material in patients with venous leg ulcers. J Am Acad Dermatol. 2012;66(6):e209-15.

23. Scherer SS, Pietramaggiori G, Matthews J, et al. Poly-N-acetyl glucosamine nanofibers: a new bioactive material to enhance diabetic wound healing by cell migration and angiogenesis. Ann Surg. 2009;250(2):322-30.

24. Scherer SS, Pietramaggiori G, Matthews JC, et al. Poly-N-acetyl glucosamine fibers induce angiogenesis in ADP inhibitor-treated diabetic mice. $J$ Trauma. 2011;71(2 Suppl 1):S183-S86.

25. Lindner HB, Zhang A, Eldridge J, et al. Anti-bacterial effects of poly-Nacetyl-glucosamine nanofibers in cutaneous wound healing: requirement for Akt1. PLoS One. 2011;6(4):e18996. Available at: http://www.ncbi.nlm.nih.gov/ pmc/articles/PMC3084735/pdf/pone.0018996.pdf. Accessed May 27, 2012

26. Falanga V, Isaacs C, Paquette D, et al. Wounding of bioengineered skin: cellular and molecular aspects after injury. J Invest Dermatol. 2002;119(3):653-60. Available at: http://www.nature.com/jid/journal/v119/ n3/pdf/5601606a.pdf. Accessed May 27, 2012.

27. Brown-Etris M, Cutshall W, Hiles MC. A new biomaterial derived from small intestine submucosa and developed into a wound matrix device. WOUNDS. 2002;14:150-66. Available at: http://www.medscape.com/viewarticle/437577. Accessed May 27, 2012. 
28. Hart J, Silcock D, Gunnigle S, Cullen B, Light ND, Watt PW. The role of oxidised regenerated cellulose/collagen in wound repair: effects in vitro on fibroblast biology and in vivo in a model of compromised healing. Int $J$ Biochem Cell Biol. 2002;34(12):1557-70.

29. Cullen B, Watt PW, Lundqvist C, et al. The role of oxidised regenerated cellulose/collagen in chronic wound repair and its potential mechanism of action. Int J Biochem Cell Biol. 2002;34(12):1544-56.

30. Cullen B, Smith R, McCulloch E, Silcock D, Morrison L. Mechanism of action of PROMOGRAN, a protease modulating matrix, for the treatment of diabetic foot ulcers. Wound Repair Regen. 2002;10(1):16-25.

31. Margolis DJ, Allen-Taylor L, Hoffstad O, Berlin JA. The accuracy of venous leg ulcer prognostic models in a wound care system. Wound Repair Regen. 2004;12(2):163-68.

32. Warriner RA. A new algorithm for the evaluation and treatment of venous leg ulcer patients in the outpatient wound care clinic. WOUNDS. 2010;56(Suppl):8-11. Available at: http://www.o-wm.com/files/Covidien_ CVRl_lr.pdf. Accessed May 27, 2012.

33. Aetna. Clinical policy bulletin: wound care. Number: 0244. Last reviewed May 13, 2011. Available at: http://www.aetna.com/cpb/medical/ data/200_299/0244.html. Accessed May 27, 2012.

34. Independence Blue Cross. Wound care: bioengineered skin substitutes. Medical policy bulletin. Policy no. 11.08.20i. Effective January 1, 2012. Available at: http://medpolicy.ibx.com/policies/mpi.nsf/0/85256AA800623D 7A85257968004F7400?OpenDocument. Accessed May 27, 2012.

35. WPS Health Insurance Medicare. Application of bioengineered skin substitutes (L30135). Updated May 3, 2012. Available at: http://www.wpsmedicare.com/part_b/policy/active/local/130135_gsurg052.shtml. Accessed May 27, 2012

36. TrailBlazer Health Enterprises. LCD 3332: bioengineered skin substitutes. Revised January 1, 2012. Available at: http://www.trailblazerhealth. com/Tools/LCDs.aspx?ID=3332. Accessed May 27, 2012.

37. UnitedHeathcare. Coverage summary. UnitedHealthcare Medicare Advantage Plans: wound treatments. Revised April 26, 2011. Available at: https://www.unitedhealthcareonline.com/ccmcontent/ProviderII/UHC/ en-US/Assets/ProviderStaticFiles/ProviderStaticFilesPdf/Tools\%20and\%20 Resources/Policies\%20and\%20Protocols/UnitedHealthcare\%20Medicare\%20 Coverage/Wound_Care_UHCMA_CS.pdf. Accessed May 27, 2012.

38. Red Book Online. Ann Arbor, MI: Thomson Reuters; 2011. Available at: http://www.redbook.com/redbook/index.html. Accessed May 27, 2012.

39. Shire Pharmaceuticals. Top-line results from pivotal trial of Dermagraft for venous leg ulcers. August 24, 2011. Available at: http://www.shire.com/shireplc/en/investors/investorsnews/irshirenews?id=519. Accessed May 27, 2012.

40. Apligraf [package insert]. Organogenesis Inc. December 2010. Available at: http://www.apligraf.com/professional/pdf/prescribing_information.pdf. Accessed May 27, 2012.

41. U.S. Food and Drug Administration. Special 510(k) summary. Oasis Wound Matrix. July 19, 2006. Available at: http://www.accessdata.fda.gov/ cdrh_docs/pdf6/K061711.pdf. Accessed May 27, 2012.
42. U.S. Food and Drug Administration. 510(k) summary. Talymed. July 28, 2010. Available at: http://www.accessdata.fda.gov/cdrh_docs/pdf10/ K102002.pdf. Accessed May 27, 2012.

43. U.S. Food and Drug Administration. Apligraf (Graftskin). Summary of effectiveness and safety data. PMA No. P950032. Organogenesis Inc. May 22, 1998. Available at: http://www.accessdata.fda.gov/cdrh_docs/pdf/ P950032b.pdf. Accessed May 27, 2011.

44. McQuay HJ, Moore RA. Using numerical results from systematic reviews in clinical practice. Ann Intern Med. 1997;126(9):712-20.

45. Cook R, Sackett D. The number needed to treat: a clinically useful measure of treatment effect. BMJ. 1995;310(6977):452-54. Available at: http:// www.ncbi.nlm.nih.gov/pmc/articles/PMC2548824/pdf/bmj05580-0046.pdf. Accessed May 27, 2012

46. Bender R. Calculating confidence intervals for the number needed to treat. Control Clin Trials. 2001;22(2):102-10.

47. Newcombe RG. Interval estimation for the difference between independent proportions: comparison of eleven methods. Stat Med. 1998;17(8):873-90.

48. Tennvall GR, Hjelmgren G, Öien R. The cost of treating hard-to-heal venous leg ulcers: results from a Swedish survey. World Wide Wounds. November 2006. Available at: http://www.worldwidewounds.com/2006/ november/Tennvall/Cost-of-treating-hard-to-heal-venous-leg-ulcers.html. Accessed May 27, 2012

49. McAlister FA. The "number needed to treat" turns 20-and continues to be used and misused. CMAJ. 2008;179(6):549-53.

50. Margolis DJ, Berlin JA, Strom BL. Which venous leg ulcers will heal with limb compression bandages? Am J Med. 2000;109(1):15-19.

51. Phillips TJ, Machado F, Trout R, Porter J, Olin J, Falanga V. Prognostic indicators in venous ulcers. J Am Acad Dermatol. 2000;43(4):627-30.

52. Meaume S, Couilliet D, Vin F. Prognostic factors for venous ulcer healing in a non-selected population of ambulatory patients. J Wound Care. 2005;14(1):31-34.

53. Milic DJ, Zivic SS, Bogdanovic DC, Karanovic ND, Golubovic ZV. Risk factors related to the failure of venous leg ulcers to heal with compression treatment. J Vasc Surg. 2009;49(5):1242-47.

54. White R. Hard-to-heal wounds: results of an international survey. Wounds UK. 2011;7(4):22-31.

55. Snyder DL, Sullivan N, Schoelles KM. Skin substitutes for treating chronic wounds (draft). Technology assessment report. Project ID: HCPR0610. Agency for Healthcare Research and Quality. December 22, 2011. Available at: http://www.elsevierbi.com/ /media/Supporting\%20 Documents/The\%20Gray\%20Sheet/38/2/skinsubstitutes_ahrq.pdf. Accessed May 27, 2012.

56. Mathias SD, Prebil LA, Boyko WL, Fastenau J. Health-related quality of life in venous leg ulcer patients successfully treated with Apligraf: a pilot study. Adv Skin Wound Care. 2000;13(2):76-78.

57. Collins L, Seraj S. Diagnosis and treatment of venous ulcers. Am Fam Physician. 2010;81(8):989-96. Available at: http://www.aafp.org/ afp/2010/0415/p989.pdf. Accessed May 27, 2012. 